\title{
Society for Pediatric Research Presidential Address 1991: Research by the Socially Conscious Pediatrician
}

\author{
STEVE KOHL \\ University of California, San Francisco and San Francisco General Yospital, Department of Pediatrics. \\ San Francisco, California 94110
}

The two main themes of my address are, first, a resolution between the perceived conflict of research versus practice for the socially conscious pediatrician and, secondly, the particular role of the pediatrician as a researcher. To summarize my conclusions, research is socially acceptable and, indeed, necessary and to serve children it must be performed in part by you-pediatricians.

Being born in the waning days of World War II, I received all of my higher education during the 1960s, that hopeful and tumultuous decade of the civil rights movement and the escalating Vietnam war. I saw medicine as a means to directly improve the health care of the underprivileged and, also, through the societal power and prestige of the physician, to have a disproportionate impact on social issues. Yet, a very significant part of me loved scientific research, pushing the boundaries of knowledge at bit further, glimpsing a new piece of truth, even if evanescent. I perceived a conflict between the direct caregiver, toiling in a ghetto clinic, who seemed to embody the compassionate, involved physician, and the cold, scientific researcher, sitting in his or her tower, surrounded by glassware and humming machines.

My years in research have definitely taught me that being a scientist does not mandate a lack of feelings or passion. Witness the discussions occurring with regularity at our meetings. More importantly, I began to appreciate the role of the researcher in the care of poor children, in an era of limited resources. It is the poor child in our society who bears the disproportionate burden of ill health. Be it the scourge of substance abuse, infections (including human immunodeficiency virus), teenage pregnancy, prematurity, or violence, the poor feel it the most. And in each of these areas, there are critical research questions, from the most basic molecular mechanisms to the broad societal area of health care delivery, all of which must be attacked in a rigorous fashion if we are to aid the poor child in a rational, effective, and efficient manner. Indeed, any research-based medical advance will disproportionately aid the poor child, inasmuch as it is that sector of our society that is so selectively burdened by ill health. The Society for Pediatric Research (SPR) state of the art symposium will be dedicated to the medical-social crisis in child health, and will highlight several of the problems we face and the role for research in helping to begin to solve these problems. I hope many of you will be in attendance. In fortuitous parallel, all of the American Medical Association journals this month are directed to the care of the poor. In particular, the American Journal of Diseases of Childhood is devoted to care of the poor child. I have authored an invited paper on behalf of the SPR pointing out the critical role of research in the effort to address this pressing need (1). The poor child is helped by both the clinician and the researcher. Surely, the time scale is different and the day to day

Supported by Grants AI2347 and HD13021 from the National Institutes of Health. proximity to the problem varies, but the results of both groups are critically necessary. Hopefully, as this nation reorders its priorities, the appearance of financial conflict between research programs and direct care programs will fall away, and enhanced cooperation will ensure the smooth transfer of technology that we so desperately need in this arena. What good is a recombinant vaccine based on the highest technology of immunology and genetic engineering if an irrational health care delivery system fails to deliver the goods to the highest need group.

For my colleagues who feel that third world medicine is a long flight away to exotic countries, I would urge them to take a short bus or subway ride to the barrio or ghetto where the infant mortality rates, the infectious disease rates, and other markers of third world life are very much in existence. In this setting, there is need and opportunity for the clinically active bench scientist, as well as the clinic-based caregiver. The intermingling of these talents will result in cross-fertilization and enhanced productivity, rigor, variety, and satisfaction.

Both bench work and clinic work are, in the end, of benefit to society. Any perceived conflict between these two is a pseudoconflict. Indeed, the wonderful flexibility of academic medicine allows me to work in the San Francisco General Hospital tuberculosis clinic in the morning and to study lymphocyte effector mechanisms in the afternoon.

The second area I would like to briefly address is, "Why the need for the pediatrician as a researcher?" We pediatricians have spent at least half of our medical school training, the bulk of a 3-year residency, and a fair portion of fellowship immersed in strictly clinically related education, which many would say doesn't add to research expertise. Wouldn't it be better, more efficient, to have most or all research performed by scientists unencumbered by the time restraints of clinical training periods and usually at least part-time clinical activities while they are doing their research? I would submit to you that there are several critical reasons for having pediatrician researchers.

Pediatricians first are interested in children. They look at a clinical situation and ask, "How can we help this child?" The same motivation is the core of their research. When I see a neonate with severe herpes, I want to know what converts a usually trivial viral infection into a lethal one in the newborn. The frustrations of the clinical arena, the limitations of our art, are the engines of motivation for our research. This is a very powerful engine indeed.

The pediatrician asks different questions. They are childrelated and often arise from our clinical experience. There are so many research questions to be answered that without the pediatrician asking the question I fear the answers for children would be very slow in coming. Well, then, why not let the pediatrician ask the questions and have someone else do the work? It is clear that the quality researcher likes to, and must, ask his or her own questions. We may start young people out in our laboratories 
working in part on our area of inquiry, but their growth and ultimate quality will depend on their refinements of intimately personal research questions. The sustained effort needed to answer a significant pediatric question is generally only made by the pediatrician researcher.

A seemingly trivial but actually critical reason to have pediatrician scientists is their access to the relevant populations and samples. It is easier, except maybe in California, to work on animals than humans and infinitely easier to work with samples from adult animals or humans than with those from children. This barrier to working with children can be a daunting one. Yet, for the pediatrician, who has spent half his or her residency starting i.v.s and drawing blood from invisible veins of sick children, there is no barrier. Not only do we have access to the child population, but indeed we are the only ones with the key. Thus, we have a special responsibility to use this population and samples from it in a sensitive and ethical manner to answer pressing questions.

The pediatrician researcher helps the children he or she studies. By making significant discoveries, therapy is altered. That is obvious. But also the act of studying a question or a population usually improves the problem even with no new discoveries at all. To the researcher, this can be particularly frustrating, first by necessitating concomitant, not historical, control groups. Even more maddening is the all too frequent event of studying the question away altogether. How often have we heard that the incidence of a particular problem in the large study was much lower than in the historical group on which sample size was based? The focus upon a population subtly improves care, heightens concern, and does all the things that we as clinicians know will result in improved outcome. It has been absolutely fascinating for me to watch the improvements of outcome of neonatal enteric meningitis wrought by 15 years of study in a collaborative fashion without a significant change in antibiotic use (2-5).

Finally, one must look at the general impact of doing research on the individual and the field as a whole. The rigorous methods of modern research demand an exactness, adherence to a reliable data base, an acknowledgment of weakness, and doubt in our techniques, samples, and often results. Research indeed is predicated on an inherent and overtly recognized incompleteness in the field of study. These same qualities, carried over to the bedside in a nonneurotic fashion, result in humility and acknowledgment of our limitations as physicians, but also fierce adherence to what we know works and healthy skepticism of the anecdotal, of the tried and true but untested. The pediatrician scientist is thus the training role model of healthy doubt, aggressive inquiry, adherence to a reliable clinical data base, and rigorous patient care. Yet, his or her recognition of the limitations in the current data base induces a humility and desire to educate patients so that they may participate in an informed way in decision making.

In my area, the basic discovery of antibody-facilitated killing of herpes-infected cells by leukocytes known as antibody-dependent cellular cytotoxicity or ADCC was made in $1974(6,7)$. For 17 years, my research has been devoted to the role of ADCC in herpes simplex infections. It was only natural that as a pediatrician I should ask about the role of this mechanism in the neonate. We thus have demonstrated in vitro defects in the ability of lymphocytes from human neonates and infants to mediate anti-herpes simplex virus $\operatorname{ADCC}(8,9)$. To develop a relevant model, we uncovered a similar defect in infant mice (10). Who else but a pediatrician and his or her staff would work with animals the size of the end of your thumb nail to answer a question? We have gone on to use the neonatal mouse model to support the in vivo relevance of human leukocyte ADCC in a xenogeneic transfer model $(11,12)$. In collaboration with other pediatricians, notably Don Anderson at Baylor College of Medicine, utilizing pediatric patient samples, we have probed the role of leukocyte adhesive glycoproteins in $\operatorname{ADCC}(13,14)$. Finally, we have begun to uncover relevant viral epitopes as ADCC targets in vitro and in vivo (15) and explore successful cytokine up-regulation of neonatal effector cell function (16).

I have had the field almost all to myself. I hope that is not because the questions are trivial, but instead because they are my questions, with my motivation, and with my unique access as a pediatrician to the relevant clinical populations and samples. This work has enriched my life and carved out a small area for me in which I am especially expert and hopefully can be particularly helpful clinically. The work has also colored my entire approach to clinical pediatrics with a rigor and cynicism bred in the laboratory. Hopefully, as we approach the time of effective immunomodulation with recombinant cytokines and epitopespecific antibody, the work from my laboratory will in small part point to interventions that will help all children and, by necessity, disproportionately help the poor child. Thus, I hope I have successfully communicated to you my resolution of research versus clinical care and, in particular, research by the socially conscious pediatrician.

I would like to thank the council members, officers, and administrative staff of the SPR for the joy of working with a wonderful group of quality and dedicated people. I would like to thank the membership of the SPR, which has allowed me this privilege and provided me with the colleagues that make this all worthwhile. Finally, I would like to thank my wife, Sybil, and my daughter, Gwynne, for their love and support.

In closing, I shall paraphrase a Hebrew meditation, "Cherish doubt, it is the handmaiden of truth, the servant of discovery, the acid which eats away the false. They that fear not doubt are founded on a rock." And, in my words, don't worry about the current relevance of your discoveries; if it is true, it will become relevant sooner than you think. And have fun in your worklife is too short not to.

Thank you all.

\section{REFERENCES}

1. Kohl S 1991 The challenge of care for the poor child. The research agenda. Am J Dis Child 145:542-543

2. Overall Jr JC 1970 Neonatal bacterial meningitis. J Pediatr 76:499-511

3. McCracken Jr GH, Mize SG 1976 A controlled study of intrathecal antibiotic therapy in gram-negative enteric meningitis of infancy. Report of the neonatal meningitis cooperative study group. J Pediatr 89:66-72

4. McCracken Jr GH. Mize SG, Threlkeld N 1980 Intraventricular gentamicin therapy in gram-negative bacillary meningitis of infancy. Report of the second neonatal meningitis cooperative study group. Lancet 1:787-791

5. McCracken Jr JH, Threlkeld N, Mize S. Baker CJ, Kaplan SL, Faingezicht I, Feldman WE, Schaad U 1984 Moxalactam therapy for neonatal meningitis due to gram-negative enteric bacilli. A prospective controlled evaluation. JAMA 252:1427-1432

6. Shore SL, Nahmias AJ, Starr SE, Wood PA, McFarlin DE 1974 Detection of cell-dependent cytotoxic antibody to cells infected with herpes simplex virus. Nature 251:350-352

7. Rager-Zisman B, Bloom BR 1974 Immunological destruction of herpes simplex virus I infected cells. Nature 251:542-543

8. Kohl S, Loo LS, Gonick B 1984 Analysis in human neonates of defective antibody-dependent cellular cytotoxicity and natural killer cytotoxicity to herpes simplex virus-infected cells. J Infect Dis 150:14-19

9. Kohl S 1983 Defective infant antiviral cytotoxicity to herpes simplex virusinfected cells. J Pediatr 102:885-888

10. Kohl S, Loo LS 1980 Ontogeny of murine cellular cytotoxicity to herpes simplex virus-infected cells. Infect Immun 30:840-847

11. Kohl S. Loo LS 1982 Protection of neonatal mice against herpes simplex virus infection. Probable in vivo antibody-dependent cellular cytotoxicity. J Immunol 129:370-376

12. Kohl S, Loo LS, Pickering LK 1981 Protection of neonatal mice against herpes simplex viral infection by human antibody and leukocytes from adult but not neonatal humans. J Immunol 127:1273-1275

13. Kohl S, Springer TA, Schmalstieg FS, Loo LS, Anderson DC 1984 Defective natural killer cytotoxicity and polymorphonuclear leukocyte antibody dependent cellular cytotoxicity in patients with LFA-1, OKM-1 deficiency. $J$ Immunol 133:2972-2978 
14. Kohl S. Loo LS. Schmalstieg FS, Anderson DC 1986 The genetic deficiency of leukocyte surface glycoprotein Mac-1, LFA-1, p150,95 in humans is associated with defective antibody-dependent cellular cytotoxicity in vitro and defective protection against herpes simplex virus infection in vivo. J Immunol 1.37:1688-1694

is. Kohl S. Strynadka NCJ. Hodges RS, Pereira L 1990 Analysis of the role of antibody-dependent cellular cytotoxicity antibody activity in murine neonatal herpes simplex virus infection with antibodies to synthetic peptides of glycoprotein D and monoclonal antibodies to glycoprotein B. J Clin Invest $86: 273-278$

16. Kohl S 1990 Protection against murine neonatal herpes simplex virus infection by lymphokine-treated human leukocytes. J Immunol 144:307-312 